\title{
Deoxyribonucleic Acid Triplex Formation Inhibits Granulocyte Macrophage Colony-stimulating Factor Gene Expression and Suppresses Growth in Juvenile Myelomonocytic Leukemic Cells
}

\author{
Marina Kochetkova, Per O. Iversen, Angel F. Lopez, and M. Frances Shannon \\ Division of Human Immunology, Hanson Centre for Cancer Research, Institute of Medical and Veterinary Science, Adelaide, 5000 South \\ Australia, Australia
}

\begin{abstract}
Juvenile myelomonocytic leukemia (JMML) is a severe childhood malignancy. The autocrine production of GMCSF is believed to be responsible for the spontaneous proliferation of JMML cells. A nuclear factor $-\kappa B(N F-\kappa B) / R e l$ binding site within the GM-CSF gene promoter, termed the $\kappa \mathrm{B}$ element, plays an important role in controlling transcription from the GM-CSF gene. We investigated the effect of an oligonucleotide GM3, directed to form a DNA triple helix across this $\kappa \mathrm{B}$ element, on growth and GM-CSF production by JMML cells. Treatment of these cells, either unstimulated or induced by $\mathrm{TNF} \alpha$, with GM3 led to a significant and specific inhibition of both GM-CSF production and spontaneous colony formation. This constitutes the first report linking specific triplex-mediated inhibition of gene transcription with a functional outcome; i.e., cell growth. We observed the constitutive presence of $\mathrm{NF}-\kappa \mathrm{B} / \mathrm{Rel}$ proteins in the nucleus of JMML cells. The constitutive and $\mathrm{TNF} \alpha$-induced $\mathrm{NF}-\kappa \mathrm{B} / \mathrm{Rel}$ complexes were identical and were composed mainly of p50 and c-Rel proteins. Treatment of the cells with a neutralizing anti-TNF $\alpha$ monoclonal antibody completely abrogated constitutive nuclear expression of $\mathrm{NF}-\kappa \mathrm{B} / \mathrm{Rel}$ proteins. These results indicate that the aberrant, constitutive GM-CSF gene activation in JMML is maintained by $T N F \alpha$-mediated activation of $N F-\kappa B / R e l$ proteins. Our findings identify the molecular basis for the autocrine TNF $\alpha$ activation of the GM-CSF gene in JMML and suggest potential novel and specific approaches for the treatment of this aggressive childhood leukemia. (J. Clin. Invest. 1997. 99:3000-3008.) Key words: malignancy • oligonucleotides • nuclear factor- $\mathrm{K} / \mathrm{Rel} \cdot$ tumor necrosis factor- $\alpha \cdot$ gene expression $\bullet$ proliferation
\end{abstract}

\section{Introduction}

The pleiotropic cytokine granulocyte macrophage colonystimulating factor is expressed in a wide range of cells, but normally only after activation (reviewed in reference 1). Activated $\mathrm{T}$ cells and monocytes, endothelial cells, and fibroblasts

Address correspondence to M. Frances Shannon, Division of Human Immunology, Hanson Centre for Cancer Research, P.O. Box 14 Rundle Mall, Adelaide, 5000 SA, Australia. Phone: 618 2223475; FAX: 618 2324092; E-mail: fshannon@immuno.imvs.sa.gov.au

Received for publication 2 August 1996 and accepted in revised form 28 March 1997.

J. Clin. Invest.

(C) The American Society for Clinical Investigation, Inc. 0021-9738/97/06/3000/09 \$2.00

Volume 99, Number 12, June 1997, 3000-3008 treated with proinflammatory cytokines are major sources of GM-CSF. In several pathological conditions, including some myeloid leukemias and chronic inflammatory disorders, GMCSF is constitutively expressed, and probably plays a role in the development and progression of these diseases (2-4).

Juvenile myelomonocytic leukemia (JMML), ${ }^{1}$ also known as juvenile chronic myelogenous leukemia, is a rare childhood malignancy (5). Its course is almost invariably fatal since both drug treatment $(6,7)$ and bone marrow transplantation (8) have given disappointing results. A prominent characteristic of this disease is that the JMML cells constitutively produce GM-CSF (9). This cytokine is thought to act as the main growth factor in JMML since antagonizing GM-CSF by neutralizing anti-GM-CSF monoclonal antibodies or the specific GM-CSF antagonist, E21R, abolish the spontaneous colony formation of JMML cells, and addition of GM-CSF to JMML cell cultures markedly enhances their growth (9-13). GM-CSF is also an important survival factor for JMML cells (13). The mechanism underlying the constitutive production of GM-CSF in JMML cells is not known, but TNF $\alpha$, which is also constitutively produced by these cells $(12,13)$, has been implicated as an autocrine regulator (12).

The ability to specifically inhibit gene transcription in cases of undesirable overproduction of a protein implicated in the pathogenesis of a disease is an attractive outcome in contemporary rational drug design. Several strategies employing short synthetic oligonucleotides as tools for the regulation of gene expression are being extensively studied with a view to potential new therapeutics (reviewed in reference 14). The so-called "antigene" strategy is based on intermolecular DNA triple helix formation on the transcriptional control elements of the gene of interest with subsequent inhibition of regulatory factor binding, which leads to altered expression (15). A number of different motifs for triplex-forming oligonucleotides (TFOs) have been described with the third strand binding predominantly to polypurine/polypyrimidine sequences in the major groove of the underlying duplex DNA (16-18). Oligonucleotide-directed triplex formation has been shown to inhibit expression of some genes such as c-myc (18), the interleukin-2 receptor $\kappa$ chain (19), and a progesterone-responsive element containing the reporter gene (20). However, a functional outcome from triplex-mediated inhibition of gene transcription has not been established.

We have recently demonstrated that a triplex-forming oligonucleotide directed to bind to the GM-CSF promoter represses GM-CSF transcription in activated Jurkat T cells (21). Expression of the GM-CSF gene in T cells is controlled by an

1. Abbreviations used in this paper: JMML, juvenile myelomonocytic leukemia; NF-кB, nuclear factor kappa B; SCF, stem cell factor; TFO, triplex-forming oligonucleotide. 
array of elements in the proximal promoter and enhancer of the gene (22-25). One of the critical elements for expression in response to $\mathrm{T}$ cell activation signals is a nuclear factor $-\kappa \mathrm{B}$ $(\mathrm{NF}-\mathrm{kB})$ element located between positions -85 and -75 in the proximal promoter $(22,23)$. This element binds members of the NF-kB/Rel family of transcription factors that have been implicated in the activation of many genes in the immune system (26). The NF-кB/Rel family of proteins currently con-

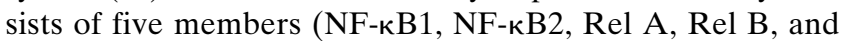
$\mathrm{c}-\mathrm{Rel}$ ) that can potentially homo- or heterodimerize to generate functionally distinct complexes (27). The triplex-forming oligonucleotide that inhibits GM-CSF transcription, GM3, binds across the NF- $\mathrm{kB}$ element and inhibits protein binding (21). The GM3 target site in the GM-CSF gene promoter also overlaps an adjacent putative binding site for the ubiquitous transcription factor Sp1, but the effect of GM3 on the binding of protein to this site or indeed its function in the GM-CSF promoter have not been described. In this study, we attempted to repress the endogenous production of GM-CSF in primary leukemic cells from patients with JMML by oligonucleotidedirected DNA triple helix formation on the GM-CSF gene promoter. We show that the TFO GM3 not only significantly and specifically inhibits GM-CSF production, but also GMCSF-dependent colony formation by JMML cells. We also provide evidence that the mechanism of transcriptional activation of GM-CSF in JMML cells involves a constitutive nuclear expression of NF- $\mathrm{B} / \mathrm{Rel}$ transcription factors that appears to be dependent on endogenous TNF $\alpha$ production by these cells.

\section{Methods}

Subjects. With parental consent, we studied three patients with diagnosed JMML and without any concurrent illness. Typically, these children (1-3 yr old) had increased white blood cell count, monocytosis, thrombocytopenia, increased fetal hemoglobin content, and hepatosplenomegaly, and all lacked the Philadelphia chromosome (4). Peripheral blood samples were also collected from two consenting, hematologically normal, adult donors. The protocol was approved by relevant ethics committees. All malignant cells used had a normal karyotype as previously described (13).
Cell preparations. Peripheral blood samples were collected when the patients had not received any treatment for at least $3 \mathrm{wk}$. Polymorphonuclear cells were removed from the samples using density centrifugation (Lymphoprep; Nycomed, Oslo, Norway) after dextran sedimentation of erythrocytes. T cells were removed from the patient samples with an anti-CD3 monoclonal antibody coupled to magnetic beads (Miltenyi Biotech, Gladbach, Germany). Monocytes from healthy donors were purified using density centrifugation followed by positive selection of the mononuclear cells with an anti-CD14 monoclonal antibody coupled to magnetic beads (Miltenyi Biotech). This method yielded preparations containing $>95 \%$ monocytes. The JMML cells and the monocytes were kept in RPMI medium supplemented with sodium bicarbonate $(0.23 \% \mathrm{wt} / \mathrm{vol})$, FCS $(10 \% \mathrm{vol} / \mathrm{vol})$, L-glutamine $(1.7 \mathrm{mM})$, penicillin $(10.5 \mathrm{mg} / \mathrm{ml})$, and gentamicin $(14 \mathrm{mg} / \mathrm{ml})$ in a humidified atmosphere with $5 \% \mathrm{CO}_{2}$ in the air.

Oligonucleotide synthesis. The sequences of double-stranded oligonucleotides, GM and Igк, used as probes for the electrophoretic mobility shift assays and single-stranded oligonucleotides, specific TFO GM3, and control GMc (18), used in this study are shown in Fig. 1.

The Sp1 consensus oligonucleotide was purchased from Promega Corp. (Madison, WI). Single-stranded 3'-propilamino-derivatized oligomers used as triplex-forming oligonucleotides were synthesized using solid support coupled with $3^{\prime}$-amino modifier (Glen Research Corp., Sterling, VA). No other stabilizing moieties were included.

Cell viability measurements. JMML cells in supplemented RPMI medium were treated with GM3 or GMc, both at $25 \mu \mathrm{M}$, every $12 \mathrm{~h}$ up to $4 \mathrm{~d}$. The numbers of dead (apoptotic) cells were quantitated every $24 \mathrm{~h}$ by EPICS-Profile II flow cytometer (Coulter Electronics, Hialeah, FL) using propidium iodide staining, as previously described (13).

Determination of cytokine production and recombinant cytokines. GM3 $(2,5,10$, or $25 \mu \mathrm{M})$, or GMc $(25 \mu \mathrm{M})$ were added to liquid cultures containing JMML cells every $12 \mathrm{~h}$ in a sterile manner. The concentrations of cytokines were assayed in supernatants collected from JMML cells $\left(10^{6}\right.$ cells $\left./ \mathrm{ml}\right)$ cultured for $48 \mathrm{~h}$. Immunoreactive cytokines were measured with the following commercial ELISA kits according to the instructions provided by the manufacturers: we performed triplicate measurements of GM-CSF (sensitivity $>0.5 \mathrm{pg} / \mathrm{ml}$; R\&D Systems, Inc., Minneapolis, MN), TNF $\alpha$ (sensitivity $>0.5 \mathrm{pg} /$ $\mathrm{ml}$; Endogen, Inc., Boston, MA), and IL-1 $\beta$ (sensitivity $>0.3 \mathrm{pg} / \mathrm{ml}$; R\&D Systems, Inc.). These ELISA kits are specific to each of the individual cytokines and no cross-reactivity is seen. We used recombinant human (rh) GM-CSF (kind gift from Genetics Institute, Cambridge, MA) and rh TNF $\alpha$ (kind gift from Genentech Inc., South San Francisco, CA).

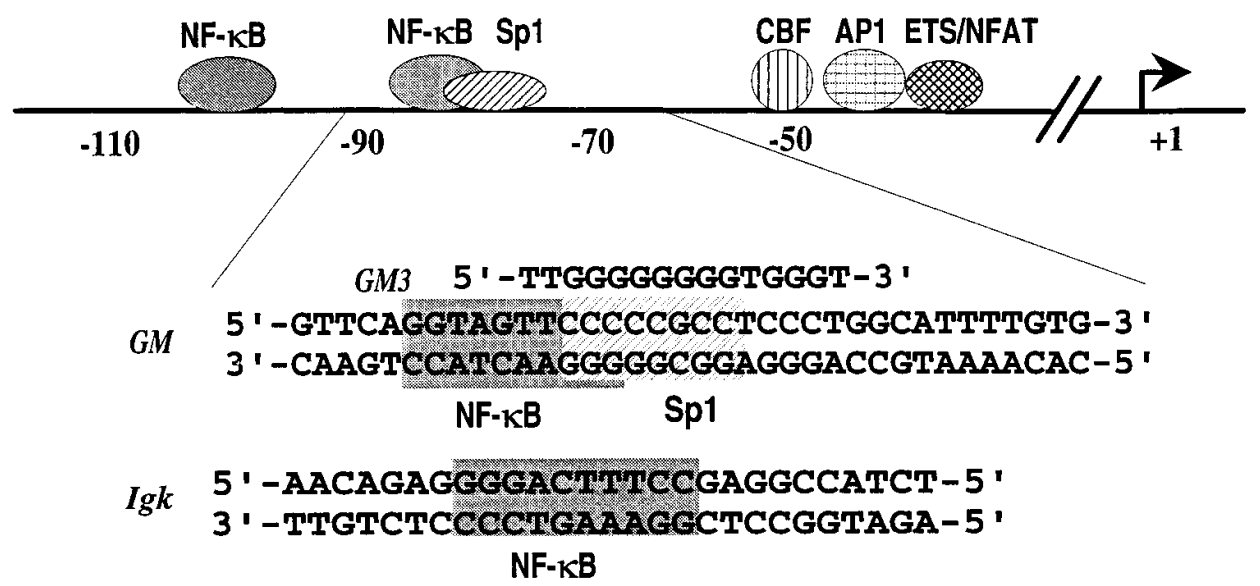

GMc 5'-GTTGTTTGGGGTGGT-3'
Figure 1. The GM-CSF proximal promoter and oligonucleotide sequences used in this study. Shaded boxes indicate previously characterized transcription factor binding sites in the GM-CSF. The transcription initiation point is shown as +1 . $\mathrm{GM}$ is a double-stranded 30-mer ( -90 to -60$)$ from the GM-CSF proximal promoter that contains the target site for triplex formation. Igא is a 27-mer (3931-3957) from the immunoglobulin $\kappa$ gene enhancer containing the NF- $\kappa \mathrm{B}$ consensus sequence. TFO GM3 (18) is aligned to its double-stranded target within the GM-CSF promoter. GMc with a random sequence of thymines and guanines was used as a nonspecific control oligomer. 
RNA analysis. Total RNA from JMML cells that had been incubated with or without TFOs for $48 \mathrm{~h}$, as outlined for cytokine production assay, was purified using guanidine isothiocyanate. The method for detecting specific mRNA by RNase protection and the vectors for antisense RNA synthesis have been described elsewhere (28). $20 \mu \mathrm{g}$ total RNA was used for each assay with ${ }^{32} \mathrm{P}$-labeled antisense probes for GM-CSF, G-CSF, and GAPDH. Samples were electrophoresed through $6 \%$ denaturing acrylamide gel, dried, and visualized using a PhosphorImager (Molecular Dynamics, Sunnyvale, CA).

Colony formation by JMML and normal bone marrow cells. Cells $\left(10^{5}\right.$ cells per culture) were plated in methylcellulose as described (29). Bone marrow cells were supplemented either with stem cell factor (SCF) and G-CSF (10 ng/ml each) to induce myeloid colonies or erythropoietin (4 ng/ml), IL-3, IL-6, and SCF (10 ng/ml each) to induce erythroid colonies, and treated with medium alone or with CM3 or GMc at the concentrations of $25 \mu \mathrm{M}$. JMML cell cultures were incubated with medium alone or treated with either GM-CSF (10 $\mathrm{ng} / \mathrm{ml}), \mathrm{TNF} \alpha(2.5 \mathrm{ng} / \mathrm{ml}), \mathrm{GM} 3(2,5,10$, or $25 \mu \mathrm{M}), \mathrm{GMc}(25 \mu \mathrm{M})$, or various combinations thereof. With sterile procedures, the oligonucleotides (GM3 and GMc) were added every $12 \mathrm{~h}$ to the cultures. Colonies ( $>40$ cells) in triplicates were scored after $14 \mathrm{~d}$.

Antibodies. Rabbit serum containing polyclonal antibodies to p65 (Rel A) and c-Rel proteins were kindly donated by Dr. Steve Gerondakis (Walter and Eliza Hall Institute, Melbourne, Australia) and have been previously characterized (30). Polyclonal antibody to p50 was supplied by Santa Cruz Biotechnology (Santa Cruz, CA). Rabbit preimmune serum was used as a negative control in the experiments with antibodies.
Cell nuclear extracts and gel shift analysis. Nuclear extracts from primary JMML cells and primary human peripheral blood monocytes, untreated or treated with $\mathrm{TNF} \alpha$ or antibodies for various time periods (see figure legends) were prepared according to the procedure previously described (31). Double-stranded oligodeoxyribonucleotides were end labeled with $\left[\gamma^{-32} \mathrm{P}\right] \mathrm{ATP}$ and T4 polynucleotide kinase and $0.2 \mathrm{ng}$ of probe was added to each DNA protein-binding reaction. Approximately $5 \mu \mathrm{g}$ of nuclear extract was used for binding assays, except for the Sp1 retardation analysis in which $\sim 2 \mu \mathrm{g}$ was used to visualize bands. The composition of the binding buffer for assays using nuclear extracts was $25 \mathrm{mM}$ Tris, $\mathrm{pH} 7.6,6 \mathrm{mM} \mathrm{MgCl}$, $0.5 \mathrm{mM}$ DTT, $0.5 \mathrm{mM}$ EDTA, 5\% (vol/vol) glycerol, $60 \mathrm{mM} \mathrm{NaCl}$, and $2 \mu \mathrm{g}$ of poly dI:dC. $50 \mathrm{ng}$ of Igк or Sp1 oligonucleotides was used in the competition experiments. To assay the effect of the triplex formation on the JMML cell nuclear protein binding double-stranded probe was initially incubated for $2 \mathrm{~h}$ at $20^{\circ} \mathrm{C}$ with GM3 or GMc at the concentrations indicated in Fig. $5 \mathrm{C}$ in $10 \mathrm{mM}$ Tris-HCl, pH 7.4, $20 \mathrm{mM}$ $\mathrm{MgCl}_{2}$, and $10 \%$ sucrose before nuclear extract was added. Electrophoresis was performed on a $5 \%$ polyacrylamide gel containing $0.5 \times$ TBE buffer for $3 \mathrm{~h}$ at $150 \mathrm{~V}$.

\section{Results}

The triplex-forming oligonucleotide GM3 reduces spontaneous and $T N F \alpha$-induced GM-CSF production in JMML cells. With confocal microscopy and fluorescently labeled oligonucleotides, we found that both the GM-CSF promoter-targeted
A

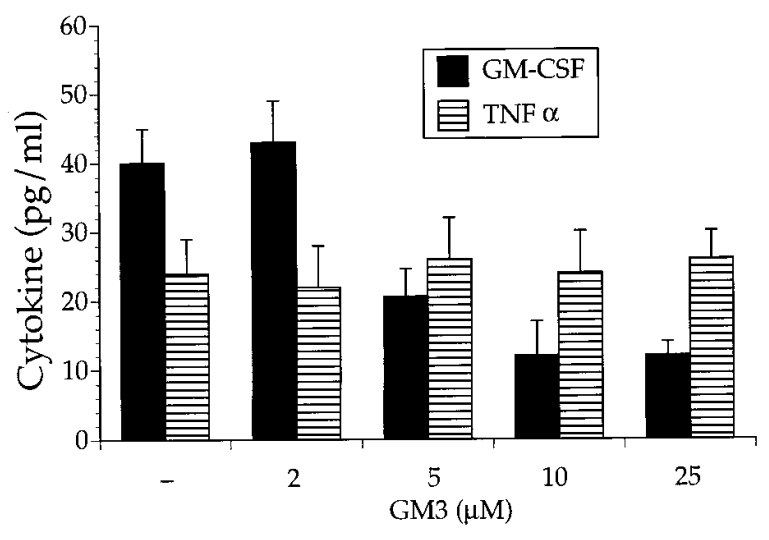

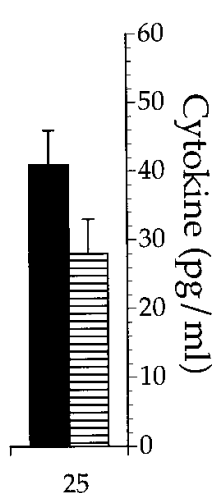

GMc ( $\mu \mathrm{M})$

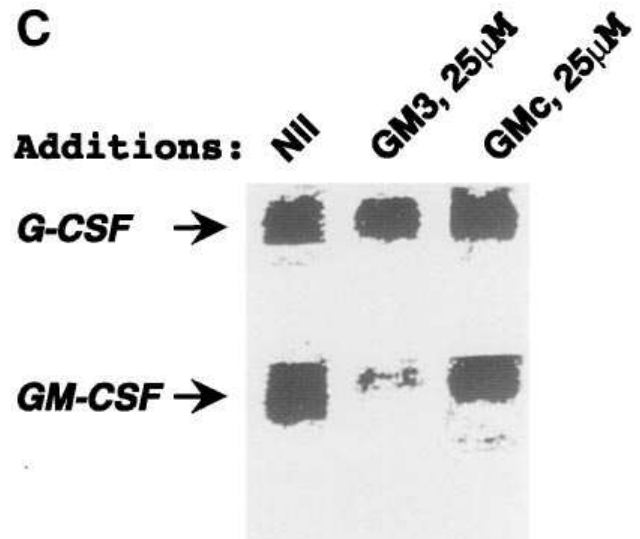

GAPDH $\rightarrow=$
B

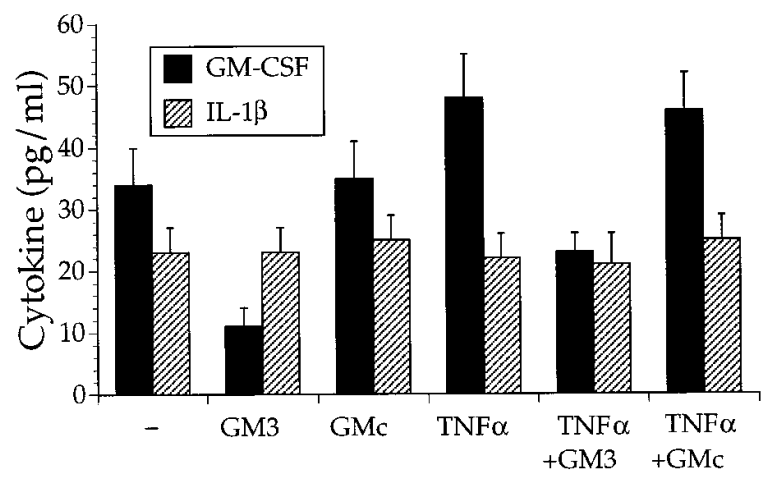

Figure 2. GM3 selectively reduces JMML cell expression of GM-CSF. (A) JMML cells were cultured with increasing doses of GM3 or a single dose of $\mathrm{GMc}$, and the supernatants were assayed for GM-CSF and TNF $\alpha$ after $48 \mathrm{~h}$. (B) JMML cells were cultured with TNF $\alpha$ with or without GM3 and GMc at $25 \mu \mathrm{M}$, and the supernatants were assayed for GM-CSF and IL-1 $\beta$ after $48 \mathrm{~h}$. Values are means \pm SEM of triplicate measurements from one JMML case and representative of two other cases. $(C)$ Total cellular RNA from untreated or treated with TFO cells was purified and the levels of specific and control mRNAs for GM-CSF, G-CSF, and GAPDH were assayed by RNase protection with ${ }^{32} \mathrm{P}$-labeled antisense probes. 
Table I. JMML Cell Viability after Treatment

With Oligonucleotides*

\begin{tabular}{lccc}
\hline & \multicolumn{3}{c}{ Oligonucleotides additions $(25 \mu \mathrm{M})$} \\
\cline { 2 - 4 } Time (h) & Nil & GM3 & GMc \\
\hline 0 & $96.6 \pm 8^{\ddagger}$ & $96.7 \pm 7$ & $95.6 \pm 9$ \\
12 & $95.5 \pm 8$ & $97.0 \pm 10$ & $95.5 \pm 8$ \\
24 & $95.2 \pm 7$ & $95.6 \pm 9$ & $95.2 \pm 7$ \\
48 & $95.5 \pm 7$ & $95.7 \pm 8$ & $95.5 \pm 7$ \\
96 & $97.7 \pm 8$ & $97.7 \pm 8$ & $97.7 \pm 8$ \\
\hline
\end{tabular}

*Data represent the percentage of surviving cells. ${ }^{\ddagger}$ Values are means \pm SEM from three different experiments. Every measurement was done in triplicate.

GM3 and the control GMc oligonucleotides were readily taken up by the JMML cells similar to the Jurkat T cells studied previously (21), and concentrated mainly in the cell nuclei (data not shown).

We examined the production of GM-CSF and TNF $\alpha$ in JMML cells cultured with the specific TFO GM3 or the control oligomer GMc for 48 h. Fig. $2 A$ shows that GM3 reduced JMML cell production of GM-CSF in a dose-dependent manner with $\sim 75 \%$ inhibition being achieved with $25 \mu \mathrm{M}$ of GM3. It is interesting to note that GM3 had close to the maximum inhibitory effect on the GM-CSF secretion by JMML cells at a concentration of $10 \mu \mathrm{M}$, and increasing amounts did not lead to any further significant inhibition of the protein production. In these assays, GM3 selectively inhibited GM-CSF gene expression since the control oligonucleotide GMc did not influence GM-CSF production even at the highest concentration $(25 \mu \mathrm{M})$, and the production of $\mathrm{TNF} \alpha$ remained unaltered in JMML cell cultures treated with GM3 (Fig. $2 A$ ).

The effect of both GM3 and GMc on cell viability was measured to ensure that the high concentrations of TFOs used were not toxic to the cells. Table I shows that over a period of $96 \mathrm{~h}$, regular (every $12 \mathrm{~h}$ ) addition of $25 \mu \mathrm{M}$ TFO did not induce any significant cell death.

The effect of exogenous TNF $\alpha(2.5 \mathrm{ng} / \mathrm{ml})$ on JMML cell production of GM-CSF was then determined. Adding TNF $\alpha$ to the cultures increased GM-CSF production by $\sim 40 \%$ compared with cells cultured in medium alone (Fig. $2 \mathrm{~B}$ ), and this $\mathrm{TNF} \alpha$-mediated increase could be blocked by simultaneously adding GM3 $(25 \mu \mathrm{M})$ to the cultures. The control oligonucleotide GMc $(25 \mu \mathrm{M})$ did not affect the stimulatory effect of TNF $\alpha$ on GM-CSF production (Fig. $2 B$ ). The production of IL-1 $\beta$ by the JMML cells did not change upon addition of TNF $\alpha$ and GM3 or GMc (Fig. 2 B). Thus, exogenous TNF $\alpha$ selectively enhanced GM-CSF gene expression in these cells. This induction was inhibited by GM3, implying that TNF $\alpha$ activates GMCSF gene transcription, which can be blocked by selective triplex formation within the GM-CSF gene promoter.

We also examined the level of mRNA for GM-CSF and G-CSF in JMML cells, untreated or cultured with either specific TFO GM3 or control oligomer GMc to determine if the effect observed on secreted protein concentrations was being mediated at the level of transcription. The level of GM-CSF but not G-CSF mRNA declined significantly in cells treated with GM3, but GMc had no detectable effect (Fig. 2C).
A

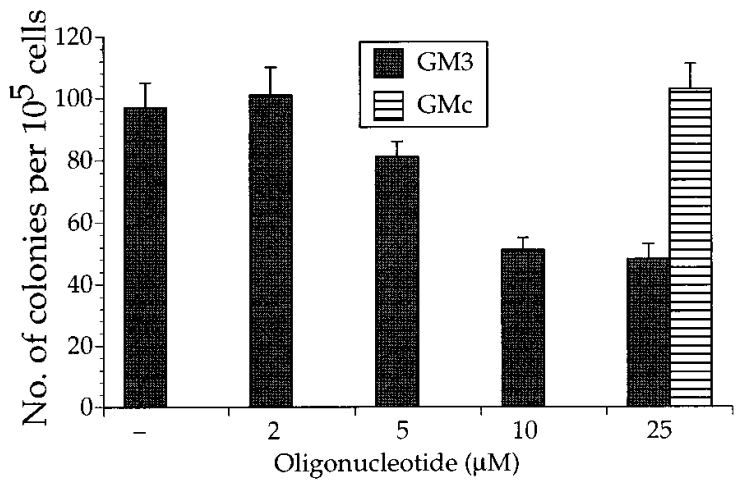

B

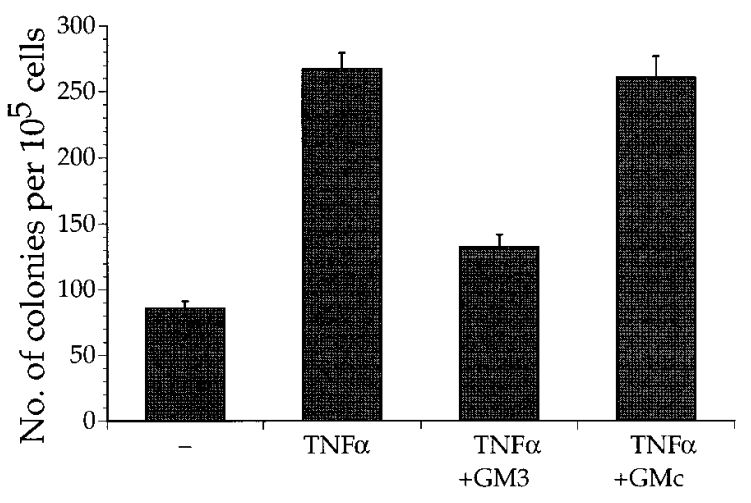

C

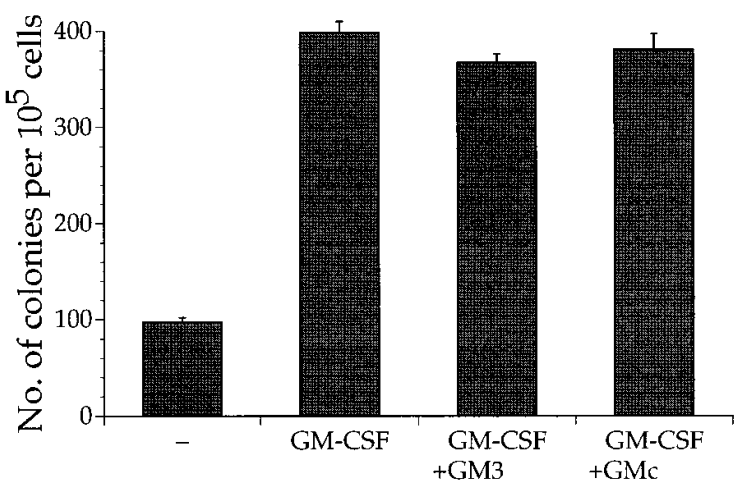

Figure 3. GM3 suppresses colony formation of JMML cells. Unstimulated $(A)$ or treated with TNF $\alpha(B)$ or GM-CSF $(C)$ JMML cells were plated with TFO GM3 or control GMc. Single-stranded oligonucleotides were added to the cultures every $12 \mathrm{~h}$ at a concentration of $25 \mu \mathrm{M}$ unless otherwise indicated. Colony numbers were recorded after $14 \mathrm{~d}$.Values are means \pm SEM of triplicate measurements from one JMML case and representative of two other cases. Note different ordinate values on each graph.

DNA-triplex formation by GM3 suppresses JMML colony formation. We next examined if the GM3 inhibitory effect on JMML cell production of GM-CSF would modulate JMML cell growth. Addition of GM3 to the cell medium suppressed spontaneous JMML colony formation in a dose-dependent manner with $\sim 45 \%$ inhibition with $10 \mu \mathrm{M}$ of the oligonucleotide, but without any significant reduction in the colony numbers upon further increase of the specific TFO levels. (Fig. 3 
Table II. Colony Formation by Normal Bone Marrow Cells Stimulated With SCF and G-CSF*

\begin{tabular}{lccc}
\hline Oligonucleotides & Nil & GM3 $(25 \mu \mathrm{M})$ & GMc $(25 \mu \mathrm{M})$ \\
Colony numbers & $43 \pm 3^{\ddagger}$ & $46 \pm 3$ & $42 \pm 5$
\end{tabular}

* Data represent typical results from two independent experiments. ${ }^{*}$ Values are mean \pm SEM from triplicate measurements.

$A$ ). Colony numbers were also unaffected by adding the control oligonucleotide GMc (Fig. 3 A). Colony type or colony morphology did not change with the inclusion of the oligonucleotides with all colonies being of the monocyte/macrophage type.

Addition of TNF $\alpha(2.5 \mathrm{ng} / \mathrm{ml})$ led to a marked increase in JMML colony formation, and this enhancement could be significantly reduced by simultaneously adding GM3 $(25 \mu \mathrm{M})$ to the cultures, while GMc $(25 \mu \mathrm{M})$ did not affect the stimulatory effect of TNF $\alpha$ (Fig. $3 \mathrm{~B}$ ). In contrast to GM3 inhibition of TNF $\alpha$-mediated stimulation of JMML cell proliferation, GM3 did not have any effect on JMML cell colony growth stimulated by addition of exogenous GM-CSF (Fig. $3 \mathrm{~B}$ ), indicating that GM3 was not interfering with the GM-CSF signaling pathway. The observed decline in JMML colony formation by GM3 was due to inhibition of proliferation and not to a decrease in JMML cell viability since separate studies showed that neither GM3 nor GMc appeared to have any cytotoxic effects on JMML cells at the highest concentration used (Table I). We assessed the effect of both GM3 and GMc on myeloid colony numbers arising from normal bone marrow grown in the presence of SCF and G-CSF (10 ng/ml each) and found no inhibition of colony growth (Table II). We also examined growth of erythroid colonies from normal bone marrow cells induced by addition of erythropoietin ( $4 \mathrm{ng} / \mathrm{ml}), \mathrm{IL}-3$, IL-6, and SCF $(10 \mathrm{ng} / \mathrm{ml}$ each) in the presence of TFOs and found no decrease in colony numbers (data not shown). These results indicate that inhibition of GM-CSF production by DNA triplex formation targeted to the $\mathrm{NF}-\kappa \mathrm{B} / \mathrm{Sp} 1$ promoter region leads to the specific repression of JMML cell growth.

$N F-\kappa B /$ Rel nuclear expression is constitutive in JMML cells. GM3 exerts its inhibitory effect on GM-CSF transcription by blocking NF- $\mathrm{B}$ and/or Sp1 protein binding to the gene promoter (21). Since GM3 inhibited both constitutive and $\mathrm{TNF} \alpha$-induced GM-CSF production and GM-CSF-dependent colony formation in JMML cells, we initially studied the pattern of constitutive and $\mathrm{TNF} \alpha$-stimulated nuclear expression of NF- $\mathrm{B} / \mathrm{Rel}$ in these cells and compared them with primary human peripheral blood monocytes. The JMML cells were found to spontaneously express NF- $\mathrm{B} / \mathrm{Rel}$ proteins in the cell nuclei (Fig. 4). If freshly washed cells were placed in medium alone, the levels of specific NF- $\mathrm{B} / \mathrm{Rel}$ binding activity gradually increased over $24 \mathrm{~h}$ of incubation without any significant change after this time point (Fig. $4 A$, lanes $1-5$ ). The specific NF-кB/DNA complex was determined by competition (data not shown) and antibody supershift (see Fig. $4 C$ ). Treatment of JMML cells with a neutralizing anti-TNF $\alpha$ monoclonal antibody, but not with preimmune serum, completely abrogated NF-кB/Rel induction (Fig. $4 A$, lane 6 ). Interestingly, addition of a neutralizing anti-GM-CSF monoclonal antibody to the cell medium (Fig. $4 A$, lane 7 ) did not have any effect on the
NF- $\mathrm{BB}$ binding activity, suggesting that $\mathrm{TNF} \alpha$ acts as an autocrine NF-кB/Rel activator in these leukemic cells.

We next studied the effect of exogenous TNF $\alpha$ on activation of the NF- $\mathrm{kB} / \mathrm{Rel}$ transcription factors in JMML cells and monocytes. Addition of TNF $\alpha(2.5 \mathrm{ng} / \mathrm{ml})$ to fresh cultures of JMML cells resulted in induction of the NF- $\mathrm{B} / \mathrm{Rel}$ nuclear expression (Fig. 4 B). Specific NF- $\mathrm{B} / \mathrm{Rel}$ binding activity was induced after $30 \mathrm{~min}$ of activation of these cells (Fig. $4 \mathrm{~B}$, lane 2) and decreased within $2.5 \mathrm{~h}$ (Fig. $4 \mathrm{~B}$, lane 3 ), resembling the pattern of induction previously described for other cell types (32).

In contrast, $\mathrm{TNF} \alpha$ had no effect on the NF-кB/Rel levels in peripheral blood monocytes from healthy donors. The electrophoretic mobility shift assay with the nuclear proteins from monocytes, untreated or stimulated with $\mathrm{TNF} \alpha$ for various times, revealed a faint band that had a similar mobility to the NF-кB-like complex (Fig. 4 B, lanes 4-7). However, addition of specific competitor or antibodies did not have any noticeable effect on this band (data not shown), suggesting that purified monocytes do not express NF- $\mathrm{B} / \mathrm{Rel}$ proteins in the cell nuclei either constitutively or in response to TNF $\alpha$.

A supershift assay with specific antibodies was used to characterize the proteins that constitute the NF-кB/Rel binding activity in nuclear extracts from unstimulated or TNF $\alpha$ stimulated JMML cells (Fig. 4 C). Antibodies specific for NF$\kappa \mathrm{B}$ proteins or preimmune serum were incubated with nuclear extracts before addition of the Igк oligonucleotide. Specific binding of the proteins from unstimulated JMML cells nuclear extracts to the $\kappa \mathrm{B}$ consensus probe was disrupted almost completely by $\mathrm{p} 50$ and c-Rel antibodies with a distinct supershift to a complex with slower mobility (Fig. $4 C$, lanes 2 and 4 ). The p65 antibody, on the other hand, produced only a faint supershift with no detectable decrease in the DNA protein complex formation (Fig. $4 C$, lane 3). The NF-кB complexes from TNF $\alpha$ treated cells also contained mainly p50 and c-Rel (Fig. $4 C$ ). It is clear from this analysis that JMML cells contain constitutive nuclear NF-кB/Rel that is dependent on endogenous $\mathrm{TNF} \alpha$ production by these cells.

GM3 inhibits NF- $\kappa B$ and Sp1 binding to the GM-CSF promoter in JMML cell extracts. Since the GM3 binding site overlaps a potential Sp1 site in the GM-CSF promoter, we also investigated whether Sp1 levels were altered in JMML cells. Using an Sp1 consensus oligonucleotide as a probe, electrophoretic mobility shift assays showed that the Sp1 binding to an $\mathrm{Sp} 1$ consensus sequence was similar in JMML cells and in monocytes under all conditions tested (Fig. $5 A$ ). We further analyzed whether Sp1 could bind to the GM-CSF promoter at the potential site adjacent to the $\mathrm{NF}-\kappa \mathrm{B}$ site. The binding of two constitutive protein complexes to the GM-CSF probe was competed by the addition of the $\mathrm{Sp} 1$ consensus oligonucleotide as a cold competitor (Fig. 5 B, lane 2). The same complexes were supershifted by the addition of an Sp1-specific antibody (Fig. 5 B, lane 3). The NF-кB/Rel complex, which migrates between these Sp1-related complexes, was eliminated with the Igк, but not the Sp1 consensus oligonucleotide (Fig. 5 $B$, lane 4).

To determine if triplex formation by GM3 affected Sp1 as well as NF- $\mathrm{B} / \mathrm{Rel}$ binding to the GM-CSF promoter, we examined the effect of the addition of GM3 or the control GMc to JMML cell nuclear extracts before electrophoretic mobility shift assays. GM3, but not GMc, inhibited the binding of both Sp1 and NF-kB/Rel to the GM-CSF promoter fragment, GM, 
A

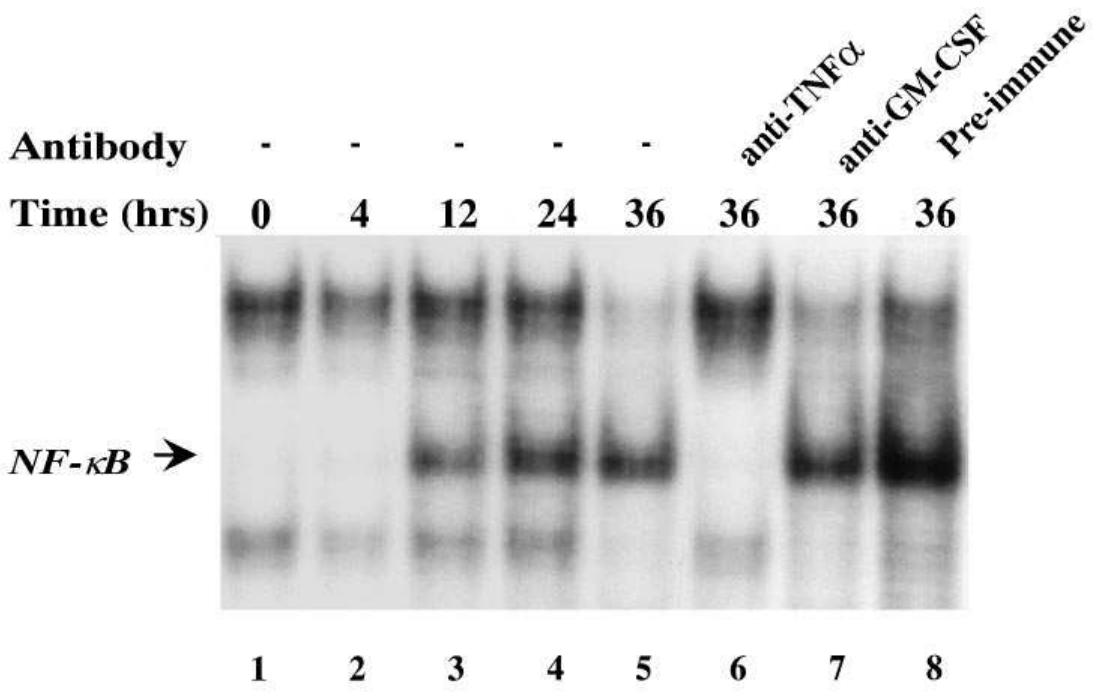

B

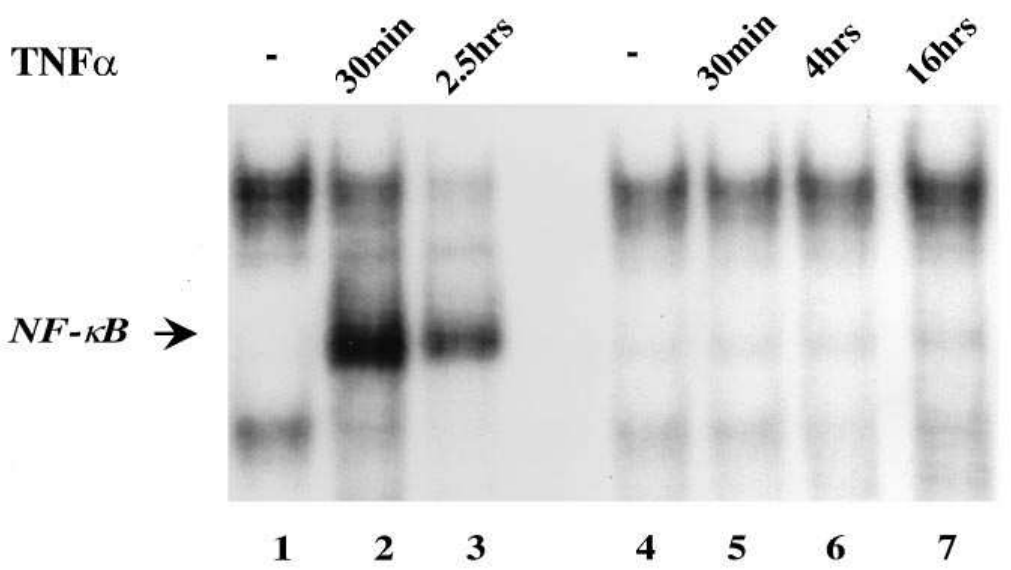

C

Antibody

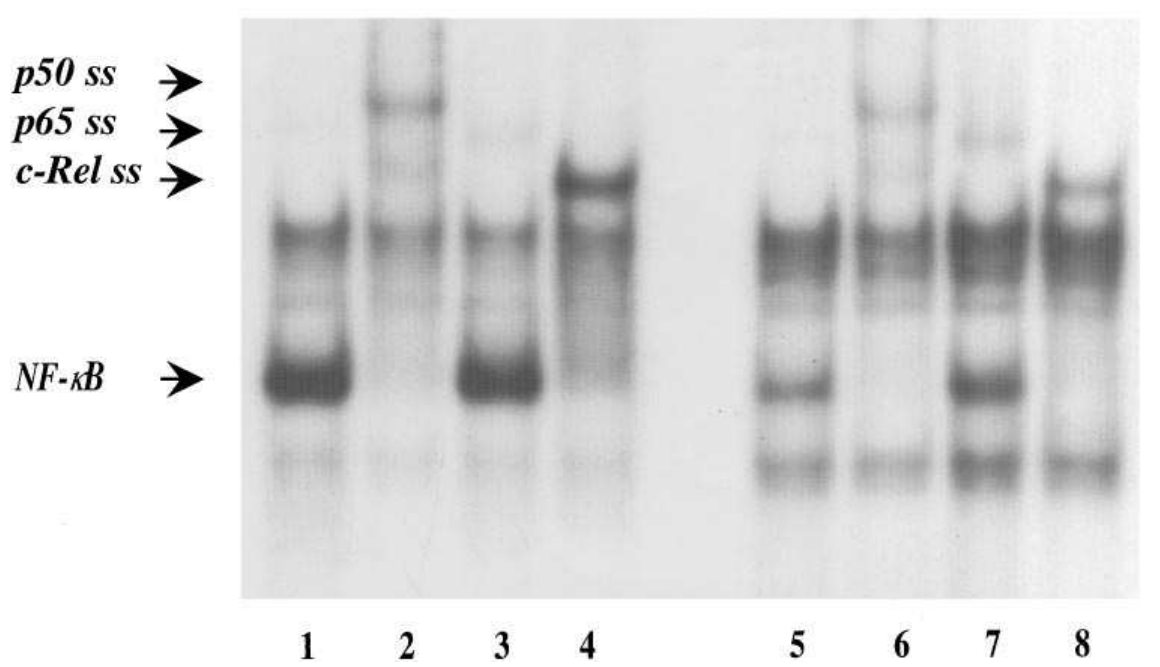

Figure 4. Gel shift analysis of the NF-кB/ Rel in JMML cells and human peripheral blood monocytes. Electrophoretic mobility shift assays were carried out using ${ }^{32} \mathrm{P}$-labeled Igк oligonucleotide $(0.2 \mathrm{ng})$ and $5 \mu \mathrm{g}$ of each nuclear extract. The figure shows only the region of the gel containing NF-кB-like DNA/protein complexes. (A) JMML cells constitutively express NF- $\mathrm{kB} / \mathrm{Rel}$ proteins in the cell nuclei. JMML cells were placed in fresh medium without growth factors and incubated for the specified time before nuclear extracts were prepared. Specific neutralizing antibody or preimmune serum were added to the samples indicated at the beginning of the incubation. (B) TNF $\alpha$ induced NF- $\kappa \mathrm{B}$ binding activity in JMML cells and monocytes. Nuclear extracts for the binding assay were prepared from JMML cells (lanes 1-3) or monocytes (lanes 4-7) unstimulated or treated with TNF $\alpha$ for the indicated time $(C)$. Identification of specific $\mathrm{NF}-\kappa \mathrm{B} / \mathrm{Rel}$ family proteins in constitutive or TNF $\alpha$-induced nuclear extracts from JMML cells. Nuclear extracts from cells either unstimulated (lanes 1-4) or treated with $\mathrm{TNF} \alpha$ were preincubated with preimmune serum or polyclonal antibody to either p50, p65, or c-Rel. Arrows indicate the NF-кB complex and specific supershifted bands. 


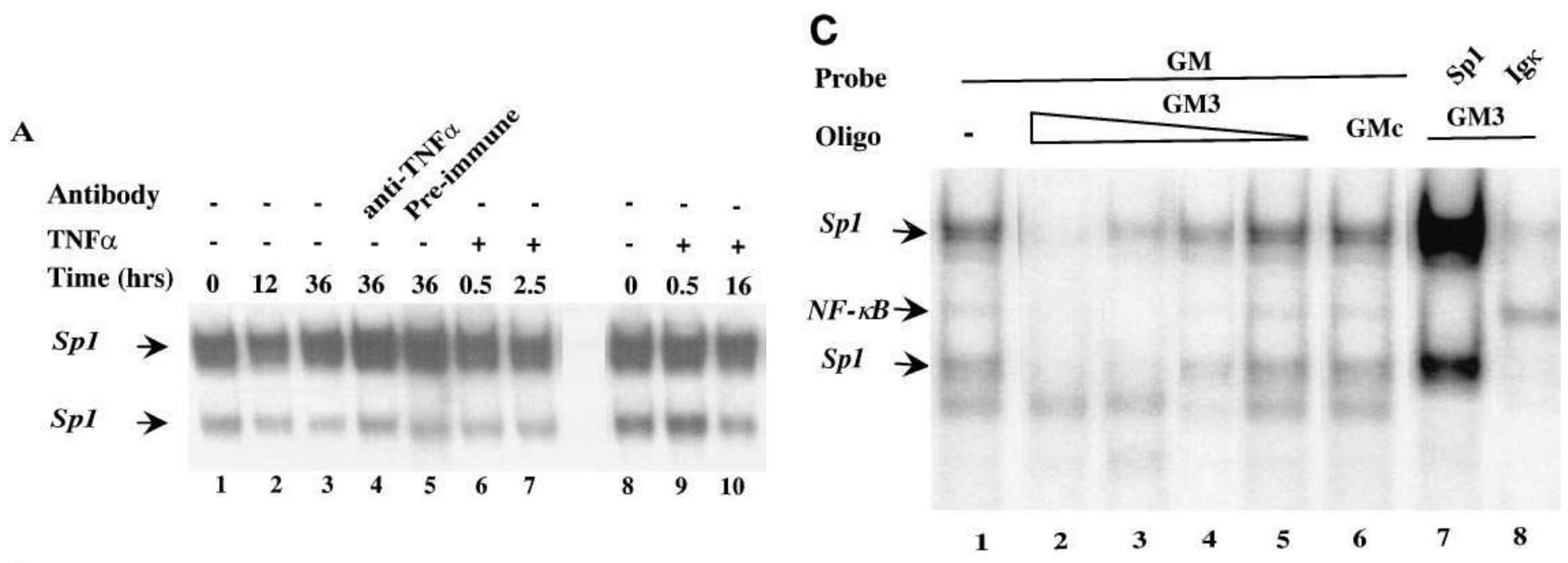

B

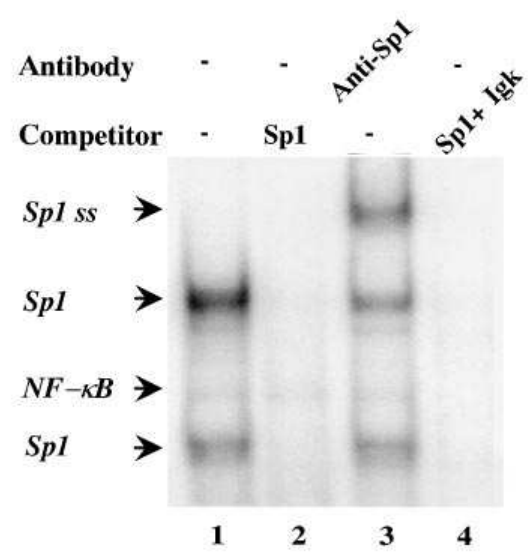

Figure 5. Analysis of Sp1 binding to the GM-CSF proximal promoter. (A) Sp1 transcription factor binding activity in JMML cells and monocytes. $0.2 \mathrm{ng}$ of the ${ }^{32} \mathrm{P}$-labeled $\mathrm{Sp} 1$ consensus oligonucleotide was incubated with JMML (lanes 1-7) or monocyte (lanes 8-10) nuclear extracts prepared from cells untreated or treated with different agents as indicated. Sp1-like complexes are shown by arrows. (B) Binding of NF- $\mathrm{kB} / \mathrm{Rel}$ and Sp1 proteins to the ${ }^{32} \mathrm{P}$-labeled GM oligonucleotide spanning the -90 to -60 region of the promoter (see Fig. 1). $5 \mu \mathrm{g}$ of nuclear extract was incubated with $0.2 \mathrm{ng}$ of the probe alone (lane 1 ), or preincubated with polyclonal anti-Sp1 antibody (lane 3) or $50 \mathrm{ng}$ oligonucleotide containing either the $\kappa \mathrm{B}(I g \kappa)$ or Sp1 consensus sequences (lanes 2 and 4, respectively) for the identification of specific DNA protein complexes. The Sp1- and NF-кB-like bands are indicated by arrows, as is the Sp1 supershifted band. (C) Effect of triplex formation on JMML cell nuclear protein binding to the GM-CSF promoter fragment $(G M)$. Double-stranded probes were preincubated alone or with single-stranded oligonucleotides, either specific TFO or control, at the following concentrations: GM3 at 10 (lanes 2, 7, and 8), 3, 1, and $0.1 \mu \mathrm{M}$ (lanes 3-5, respectively) and GMc at $10 \mu \mathrm{M}$ (lane 6), followed by addition of $5 \mu \mathrm{g}$ nuclear extracts from unstimulated JMML cells. Complexes were analyzed on 5\% nondenaturing polyacrylamide gels. in a dose-dependent manner (Fig. $5 C$, lanes 2-5), whereas it had no effect on the binding of either Sp1 or NF-кB to their consensus sequences (Fig. $5 C$, lanes 7 and 8 ). These results show firstly that the levels of Sp1 are not grossly altered in JMML cells, and secondly that inhibition of Sp1 binding to the gene promoter by triple helix formation may contribute together with an effect on NF-кB in the GM3 inhibition of GM$\mathrm{CSF}$ production and cell growth.

\section{Discussion}

In this report, we show that the DNA triplex-forming oligonucleotide GM3, directed to recognize a target on the GM-CSF promoter, reduced the growth of JMML cells concomitant with a marked decrease of GM-CSF production by these cells. GM3 exerted a selective inhibitory effect on GM-CSF gene expression since the secretion of both TNF $\alpha$ and IL-1 $\beta$ by JMML cells cultured with GM3 remained unaltered. The specific triplex formation by GM3, targeted to the $\mathrm{NF}-\kappa \mathrm{B} / \mathrm{Sp} 1$ binding sites within the GM-CSF promoter, is in accordance with recent data from our experiments in the human Jurkat $\mathrm{T}$ cell line where GM-CSF, but not IL-3, expression was inhibited (21). TNF $\alpha$ markedly stimulated the production of GMCSF and JMML colony formation and these effects could also be selectively blocked by GM3. Furthermore, we show that JMML cells constitutively express NF-кB/Rel proteins in the cell nuclei, providing the molecular basis for the inhibitory ef- fect of TFO GM3 on the spontaneous colony formation by these cells. To our knowledge, this is the first report describing an effect of triplex formation on cell function as a result of selective inhibition of gene transcription.

There is firm evidence that GM-CSF is an important growth and survival factor for JMML cells (9-13). Moreover, mice overexpressing murine GM-CSF develop symptoms that resemble those found in JMML patients (33). The data presented here strengthen the model of GM-CSF as an autocrine growth factor for JMML cells since specific inhibition of GMCSF transcription by triplex formation on the promoter translates into an inhibition of growth. TNF $\alpha$ has also been implicated as an important growth factor for JMML cells $(12,13)$. One of the mechanisms by which TNF $\alpha$ is thought to influence JMML cell growth is through the activation of GM-CSF production (12). We show here that the TNF $\alpha$-induced growth of the JMML cells can be markedly decreased by inhibition of GM-CSF transcription by the triplex forming oligonucleotide GM3. TNF $\alpha$ treatment also leads to increased GM-CSF production by these cells and it appears that one of the mecha-

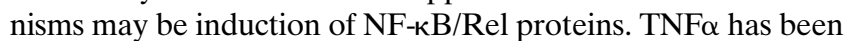
shown to induce NF-кB/Rel proteins in many cell types (27). In JMML cells, it appears that the constitutive presence of NF$\kappa \mathrm{B} / \mathrm{Rel}$ in the nucleus is dependent on $\mathrm{TNF} \alpha$ since a monoclonal antibody to TNF $\alpha$ can block this effect. The GM-CSF promoter has two well defined NF-кB sites in its promoter (23, 24) and so it is likely that constitutive NF- $\mathrm{B} / \mathrm{Rel}$ in the nucleus will activate the GM-CSF promoter. The constitutive and 
$\mathrm{TNF} \alpha$-induced NF-кB in the JMML cells appear primarily to be composed of a heterodimer of p50 and c-Rel. There is another recent report of constitutive NF-кB in myeloid leukemias, but there the complex was composed of the classical p50 and p65 heterodimer (34). It was shown that in these cells constitutive NF- $\mathrm{kB}$ correlated with the spontaneous production of IL-1 and IL-6. It has recently been documented that c-Rel is critical for GM-CSF induction since mice lacking c-Rel expression have a significant impairment in their ability to produce GM-CSF in activated T cells (35). We have also shown that the NF-кB sites in the GM-CSF promoter can bind c-Rel under specific activation conditions (36). These findings imply that the activation of $\mathrm{c}-\mathrm{Rel}$ by $\mathrm{TNF} \alpha$ might be a critical event driving GM-CSF expression and hence growth of the JMML cells. We have shown that overexpression of NF-кB p65 (Rel A) alone, however, is not sufficient to activate the GM-CSF promoter, at least in T cells, but together with other activation signals, such as an activated mutant Ras, it can lead to GM-CSF transcription (22). The presence of constitutive NF-кB together with other signaling defects in these cells may lead to constitutive GM-CSF or TNF $\alpha$ expression. Alternatively, the presence of c-Rel alone rather than p65 in these cells may be sufficient to activate the GM-CSF promoter.

GM3 also inhibits the binding of Sp1 to the GM-CSF promoter and this Sp1 site plays a role in GM-CSF promoter function. There was, however, no difference in the level of Sp1 in JMML cells compared with normal monocytes, indicating that it is unlikely that $\mathrm{Sp} 1$ is the cause of abnormal production of GM-CSF in leukemic cells. The fact that inhibiting both NF$\kappa \mathrm{B}$ and SP-1 binding to the promoter lead to only a $50 \%$ decrease in cell proliferation implies that other transcription factors are also involved. Such factors as AP-1, Ets, NFAT, and $\mathrm{CBF}$ all play a role in GM-CSF promoter function, and their status in the JMML cells has not yet been investigated.

The $\mathrm{TNF} \alpha$ promoter also contains NF- $\mathrm{B} / \mathrm{Rel}$ binding sites and $\mathrm{NF}-\kappa \mathrm{B}$ has been shown to be important in transcription from the TNF $\alpha$ gene (37). Therefore NF-кB may also function in an autocrine feedback loop for the TNF $\alpha$ gene. On the other hand, GM-CSF activation of the cells does not appear to affect the NF- $\mathrm{B} / \mathrm{Rel}$ levels in the JMML cells since blocking GM-CSF function with a specific antibody did not reduce NF$\mathrm{\kappa B} / \mathrm{Rel}$ nuclear expression. Thus, the nature of the primary defect that establishes this autocrine TNF $\alpha / N F-\kappa B / G M-C S F$ pathway in the JMML cells remains to be clarified.

The abundant evidence linking GM-CSF to the uncontrolled cellular growth in JMML strongly suggests that agents inhibiting GM-CSF-mediated activity might be useful in controlling this aggressive childhood malignancy. Our results imply that one can modify leukemic cell growth by suppressing gene transcription using short oligonucleotides. While this approach may lead to potential novel therapeutics, it also provides a useful tool for the dissection of altered mechanisms of gene transcription in JMML. Oligonucleotides are increasingly being viewed as tools for inhibition of the expression of the implicated protein in in vitro and in vivo models of various diseases including leukemia (reviewed in references 38, 39), and a number of clinical trials are currently under way. Methods for the improved delivery and increased in vivo stability of these agents are extensively being investigated with considerable success $(40,41)$. Future studies need to establish the efficacy and safety of these triplex-forming oligonucleotides for use in vivo.

\section{Acknowledgments}

GM-CSF was a gift from Genetics Institute, and TNF $\alpha$ was a gift from Genentech Inc.

This study was financed in part by the Anti-Cancer Foundation of South Australia and the National Health \& Medical Research Council of Australia. P.O. Iversen holds a fellowship with the Norwegian Cancer Society.

\section{References}

1. Gasson, J.C. 1991. Molecular physiology of granulocyte-macrophage colony stimulating factor. Blood. 77:1131-1145.

2. Russell, N.H. 1992. Autocrine growth factors and leukaemic haemopoesis. Blood Rev. 6:149-156.

3. Young, D.C., K. Wagner, and J.D. Griffin. 1987. Constitutive expression of the granulocyte-macrophage colony stimulating factor gene in acute myeloblastic leukemia. J. Clin. Invest. 79:100-106.

4. Xu, W., G.S. Firestein, R. Taetle, K. Kaushansky, and N.J. Zvafler. 1989. Cytokines in chronic inflammatory arthritis. II. GM-CSF in rheumatouid synovial effusions. J. Clin. Invest. 83:876-882.

5. Castro-Malaspina, H., G. Schaison, S. Passe, A. Pasquier, R. Berger, C. Bayle-Weisgerber, D. Miller, M. Seligmann, and J. Bernard. 1984. Subacute and chronic myelomonocytic leukemia in children (juvenile CML). Cancer. 54: 675-686.

6. Castleberry, R.P., P.D. Emanuel, K.S. Zuckerman, S. Cohn, L. Strauss, R.L. Byrd, A. Homans, S. Chaffee, R. Nitschke, and R.J. Gualtieri. 1994. A pilot study of isoretinoin in the treatment of juvenile chronic myelogenous leukemia. N. Engl. J. Med. 331:1680-1684.

7. Chan, H.S.L., Z. Estrov, S.S. Weitzman, and M.H. Freedman. 1987. The value of intensive combination chemotherapy for juvenile chronic myelogeneous leukemia. J. Clin. Oncol. 5:1960-1967.

8. Sanders, J.E., C.D. Buckner, E.D. Thomas, R. Fleischer, K.M. Sullivan, F.A. Appelbaum, and R. Storb. 1988. Allogeneic marrow transplantation for children with juvenile chronic myelogenous leukemia. Blood. 71:1144-1146.

9. Emanuel, P.D., L.J. Bates, S.-W. Zhu, R.P. Castleberry, R.J. Gualtieri, and K.S. Zuckerman. 1991. The role of monocyte-derived hemopoietic growth factors in the regulation of myeloproliferation in juvenile chronic myelogenous leukemia. Exp. Hematol. (Charlottesv). 19:1017-1024

10. Emanuel, P.D., L.J. Bates, R.P. Castleberry, R.J. Gualtieri, and K.S. Zuckerman. 1991. Selective hypersensitivity to granulocyte-macrophage colony-stimulating factor by juvenile chronic myeloid leukemia hematopoietic progenitors. Blood. 77:925-929.

11. Gualtieri, R.J., P.D. Emanuel, K.S. Zuckerman, G. Martin, S.C. Clark, R.K. Shadduck, R.A. Dracker, J. Akabutu, R. Nitschke, M.L. Hetherington, et al. 1989. Granulocyte-macrophage colony-stimulating factor is an endogeneous regulator of cell proliferation in juvenile chronic myelogenous leukemia. Blood. 74:2360-2367.

12. Freedman, M.H., A. Cohen, T. Grunberger, N. Bunin, R.E. Luddy, E.F. Saunders, N. Shahidi, A. Lau, and Z. Estrov. 1992. Central role of tumour necrosis factor, GM-CSF, and interleukin 1 in the pathogenesis of juvenile chronic myelogeneous leukaemia. Br. J. Haematol. 80:40-48.

13. Iversen, P.O., R.L. Rodwell, L. Pitcher, K.M. Taylor, and A.F. Lopez. 1996. Inhibition of proliferation and induction of apoptosis in juvenile myelomonocytic leukemic cells by the granulocyte-macrophage colony-stimulating factor analogue E21R. Blood. 80:479-486.

14. Stull, R.A., and F.C. Szoka. 1995. Antigene, ribozyme and aptamer nucleic acid drugs: progress and prospects. Pharm. Res. (NY). 12:465-483.

15. Helene, C., N.T. Thuong, and A. Harrel-Bellan. 1992. Control of gene expression by triple helix-forming oligonucleotides. The antigene strategy. Ann. NY Acad. Sci. 660:27-36.

16. Moser, H.E., and P.B. Dervan. 1987. Sequence-specific cleavage of double helical DNA by triple helix formation. Science (Wash. DC). 238:645-650.

17. Beal, P.A., and P.B. Dervan. 1991. Second structural motif for recognition of DNA by oligonucleotide-directed triple helix formation. Science (Wash. DC). 251:1360-1363.

18. Cooney, M., C. Chernuszewicz, E.H. Postel, S.J. Flint, and M.E. Hogan. 1988. Site-specific oligonucleotide binding represses transcription of the human c-myc gene in vitro. Science (Wash DC). 241:456-459.

19. Grigoriev, M., D. Praseuth, A.L. Guieysse, P. Robin, N.T. Thuong, C. Helene, and A. Harrel-Bellan. 1993. Inhibition of gene expression by triple helix-directed DNA cross-linking at specific sites. Proc. Natl. Acad. Sci. USA. 90: 3501-3505.

20. Ing, N.H., J.M. Beekman, D.J. Kessler, M. Murphy, K. Jayaraman, J.G. Zendegui, M.E. Hogan, B.W. O'Malley, and M.-J. Tsai. 1993. In vivo transcription of a progesterone-responsive gene is inhibited by a triplex forming oligonucleotide. Nucleic Acids Res. 21:2789-2796.

21. Kochetkova, M., and M.F. Shannon. 1996. DNA triplex formation selectively inhibits granulocyte-macrophage colony-stimulating factor gene expres- 
sion in human T cells. J. Biol. Chem. 271:14438-14444.

22. Jenkins, F., P.N. Cockerill, D. Bohmann, and M.F. Shannon. 1995. Multiple signals are required for function of the human GM-CSF gene promoter in T cells. J. Immunol. 155:1240-1251.

23. Himes, S.R., L.S.Coles, R. Katsikeros, R.K.Lang, and M.F. Shannon. 1993. HTLV-1 tax activation of the GM-CSF and G-CSF promoters requires the interaction of NF-кB with other transcription factor families. Oncogene. 8: 3189-3197.

24. Shannon, M.F., S.R. Himes, and L.S. Coles. 1995. GM-CSF and IL-2 share common control mechanisms in response to costimulatory signals in T-cells. J. Leukocyte Biol. 57:1-7.

25. Cockerill, P.N., M.F. Shannon, A.G. Bert, G.R. Ryan, and M.A.Vadas. 1993. The GM-CSF/IL-3 locus is regulated by an inducible cyclosporin A-sensitive enhancer. Proc. Natl. Acad. Sci. USA. 90:2466-2470.

26. Miyamoto, S., and I.M. Verma. 1995. Rel/NF-кB/IкB story. Adv. Cancer Res. 46:255-292.

27. Siebenlist, U., G. Franzoso, and K. Brown. 1994. Structure, regulation and function of NF-кB. Annu. Rev. Cell Biol. 10:405-455.

28. Brown, C.Y., K.A. Lagnado, M.A. Vadas, and G.Y. Goodall. 1996. Differential regulation of the stability of cytokine mRNAs in lipopolysaccharideactivated blood monocytes in response to interleukin-10 J. Biol. Chem. 271: 20108-20112.

29. Haylock, D.N., L.B. To, T.L. Dowse, C.A. Jutner, and P.J. Simmons. 1992. Ex vivo expansion and maturation of peripheral blood CD $34^{+}$cells in to myeloid lineage. Blood. 80:1405-1412.

30. Grumont, R.J., and S. Gerondakis. 1994. The subunit composition of NF-кB complexes changes during B-cell development. Cell Growth Differ. 5: 1321-1331.

31. Schreiber, E., P. Matthias, M.M. Muller, and W. Schaffner. 1989. Rapid detection of octamer binding proteins with 'mini extracts', prepared from a small number of cells. Nucleic Acids Res. 17:6419.
32. Wu, H., and G. Lozano. 1994. NF-кB activation of p53. J. Biol. Chem. 269:20067-20074.

33. Lang, R.A., D. Metcalf, R.A. Cuthbertson, I. Lyons, E. Stanley, A. Kelso, G. Kannourakis, D.J. Williamson, G.K. Klintworth, T.J. Gonda, and A.R. Dunn. 1987. Transgenic mice expressing a hemopoietic growth factor gene (GM-CSF) develop accumulations of macrophages, blindness. and a fatal syndrome of tissue damage. Cell. 51:675-686.

34. Dokter, W.H., L. Tuyt, S.J. Sierdsema, M.T. Esselink, and E. Vellenga. 1995. The spontaneous expression of IL-1 $\beta$ and IL-6 is associated with spontaneous expression of AP-1 and NF- $\mathrm{B}$ transcription factor in acute myeloblastic leukemia cells. Leukemia (Baltimore). 9:425-432.

35. Gerondakis, S., A. Strasser, D. Metcalf, G. Grigoriadis, J.-P.Y. Schreelinck, and R.J. Grumont. 1996. Rel-deficient T cells exibit defects in the production of IL-3 and GM-CSF. Proc. Natl. Acad. Sci. USA. 93:3405-3409.

36. Himes, S.R., R. Katsikeros, and M.F. Shannon. 1996. Costimulation of cytokine gene expression in T cells by the HTLV-1 trans-activator Tax. J. Virol. 70:4001-4008.

37. Drouet, C., A.N. Shakhov, and C.V. Jongeneel. 1991. Enhancers and transcription factors controlling the inducibility of the TNF $\alpha$ promoter in primary macrophages. J. Immunol. 147:1694-1700.

38. Mirabelli, C.K., C.F. Bennett, K. Anderson, and S.T. Crooke. 1991. In vitro and in vivo pharmacologic activities of antisense oligonucleotides. AntiCancer Drug Des. 6:647-661.

39. Maher, L.J., III. 1996. Prospects for the therapeutic use of antigene oligonucleotides. Cancer Invest. 14:66-82.

40. Dugunes, N., and P.L. Felgner. 1993. Intracellular delivery of nucleic acids and transcription factors by cationic liposomes. Methods Enzymol. 221:303-306.

41. Guy-Caffey, K.J., V. Bodepudi, S.J. Bishop, K. Jayaraman, and N. Chaudhary. 1995. Novel polyaminolipids enhance the cellular uptake of oligonucleotides. J. Biol. Chem. 270:31391-31396. 